\title{
The Common Operational Picture as Collective Sensemaking
}

\section{Jeroen Wolbers* and Kees Boersma**}

*Department of Organization Sciences, VU University Amsterdam, De Boelelaan 1081, 1081 HV Amsterdam, The Netherlands. E-mail: j.j.wolbers@vu.nl

**Department of Organization Sciences, VU University Amsterdam, De Boelelaan 1081, 1081 HV

Amsterdam, The Netherlands. E-mail: f.k.boersma@vu.nl

The common operational picture is used to overcome coordination and information management problems during emergency response. Increasingly, this approach is incorporated in more advanced information systems. This is rooted in an 'information warehouse' perspective, which implies information can be collected, sorted and exchanged in an accessible and univocal form. In practice, however, professionals interpret similar information differently. Therefore, we focus on how emergency responders develop collective sensemaking from information. We employ a 'trading zone' perspective, in which information is negotiated, to study information management in an ethnographic study of disaster exercises in the Netherlands. Our analysis shows how professionals attribute different meanings to information that distorts the coordination process. We end by stressing the importance of actionable knowledge and reflexivity.

\section{The problem of information management during emergency response}

'Once asbestos is part of the incident a whole new procedure has to be started up. What I need is our hazardous materials expert on the spot as soon as possible. I know about some of the asbestos procedures, and what should happen, but I think it is very important for us to ask for expert knowledge. I had the feeling the fire officer made the decisions very quickly by himself. He has taken measurements because of the asbestos: he took care of the decontamination on the street. It was like:"I do this" and "I do that" ... I had the feeling that the fire fighters were not collaborating with others. If I knew about that asbestos earlier I would have responded differently but they didn't tell us. "You didn't know this was relevant for us? Excuse me!"” his quote is from an officer who represents the
municipal authorities. He made this remark as a
reaction to a fire officer's action during a training
session. It indicates that emergency response organiza-
tions rely upon each other's information to align work
processes. At the same time, the quote reveals that
the representatives of the different professions often
'forget' to share information because they tend to
operate within their own professional 'silos'.
It is well documented that emergency response
organizations struggle with information sharing, com-
munication and coordination (Bharosa, Lee, \& Janssen,
2010; Comfort, 2007; Netten \& Van Someren, 2011;
Quarantelli, 1997). During emergency response opera-
tions, organizations with different backgrounds, special-
ized operational expertise and different professional
languages need to coordinate their actions across juris-
dictional and organizational boundaries (Comfort \&
Kapucu, 2006). This coordination problem is even more 
challenging because each response organization has operational field units at different levels, different functional command structures and separate back offices for information and resource management (Kapucu, 2006; Moynihan, 2009).

Adequate information management is regarded as crucial to overcome problems with coordination and information sharing between different organizational domains (Donahue \& Tuohy, 2006; Manzi, Powers, \& Zetterlund, 2002) and is an important part of the response organizations' information sharing culture (Marincioni, 2007; Schooley \& Horan, 2007). Encouraging the willingness to share information is believed to support collaboration and could foster organizational learning and facilitate adaptation and improvisation (Waugh \& Streib, 2006). However, failing communication and inadequate coordination between organizations, across levels and between back offices are also often blamed for problems with information management, such as information overload (Bharosa et al., 2010), difficulties with information technology in-use (Quarantelli, 1997), insufficient evaluation/validation of the information (Rake \& Nja, 2009) and insufficient attention for sharing data with others (Dearstyne, 2007).

Paradoxically, information management is seen as both the problem and the solution for reaching sufficient situational awareness to support coordination. Emergency management agencies try to solve the information management problem by advocating more advanced and better-equipped information systems. The promise is that these systems should support its users to reach shared situational awareness by creating a common operational picture (COP) (Comfort, 2007; Endsley, 1995). Examples are time critical information systems (Schooley \& Horan, 2007) and systems from the logic of Netcentric Enabled Capabilities (Boersma, Wagenaar, \& Wolbers, 2012). To solve the information management problem, the focus is put on building system architectures, in which the need is stressed for integration and linkage of information, fast access, timeliness, updating of information and standardization of information (Meissner, Luckenbach, Risse, Kirste, \& Kirchner, 2002).

Yet, the focus on building system architectures overlooks the social aspect of sharing and interpreting information. The different expertise of the emergency responders requires them to first develop common ground from which they can interact with each other (Clark \& Brennan, 1991). For example, Morris, Morris, and Jones (2007) described that the reason behind the success of the coast guard forces in accomplishing one of the few effective initial responses to hurricane Katrina was the attention to cooperation, adaptation, and flexibility in the work of the coast guard that "embraced the many languages of other stakeholder organizations' (Morris et al., 2007, p. 101). Learning how to bring together each other's complementary skills, learning from the experience of others and closely examining information (Moynihan, 2008) is regarded as highly consequential for successful information sharing. Therefore, in order to understand how first responders interpret each other's needs and requirements for coordination, a sensemaking perspective on information sharing is necessary to capture the ambiguity of information, the presence of multiple perspectives and the role of representations in the common operational picture (Houghton, Leedom, \& Miles, 2002; Weick, Sutcliffe, \& Obstfeld, 1999).

In this article, we are interested in the question how the different emergency response organizations share information about their actions and the ongoing crisis, how they give meaning to the information, and how the information, is articulated in their narratives. Our main question is: How do emergency responders make sense of exchanged information and how does this affect their shared situated understanding of the emergency situation and response?

The data collection for this article took place in the Netherlands during exercises for commanding officers in a field command centre aimed at creating a common operational picture. As the coordination problems between Dutch emergency response organizations are not unique (i.e., they also exist elsewhere), we think this article has more general lessons to offer.

The article is organized as follows. We will first present a theoretical discussion to uncover the different perspectives of information sharing in the emergency management literature. Next, we will explain our methodology in Section 3 and continue with the description of the findings in Section 4. Here we will present three cases that illustrate how sensemaking plays a crucial role in the information sharing practices of emergency responders. We end our argument by presenting a discussion about the importance and implications of taking a sensemaking perspective on information sharing in emergency management research.

\section{From an 'information warehouse' towards a 'trading zone'}

The COP is considered as one of the most promising solutions in emergency management to improve the quality of information sharing and to support the development of situational awareness (Comfort, 2007). The COP is often manifested as a geographical representation combined with a checklist that describes the characteristics of the response operation. Despite its common use in emergency management, a univocal definition of the COP lacks both in the field and in the literature. There are disagreements as to whether the COP is a product, process or operating environment 
(Copeland, 2008). Roughly two types of definitions can be distinguished: one that focuses on capabilities of information dissemination and another that stresses the need for reaching a sufficient level of shared understanding.

An example of the first type of definition is the way in which the COP is described in the US National Incident Management System: 'a common operational picture is established and maintained by the gathering, collating, synthesizing, and disseminating of incident information to all appropriate parties involved in an incident. Achieving a common operating picture allows on-scene and off-scene personnel to have the same information about the incident, including the availability and location of resources, personnel, and the status of requests for assistance' (FEMA, 2009, p. 4.5). In this definition, the COP is treated as a means to capture information and putting it in a place where it can easily be accessed. The COP is treated as a solution to the problem of incomplete information, whereby making information better and more widely accessible solves the issue at hand. As a result, the current generation of COP is treated as an 'information warehouse' where its users can select the information that is appropriate for them to perform their tasks (Leedom, 2003). In the information warehouse, 'information useful to processes is stored ... in an easy and accessible form' (Davenport, 1993, p. 89), whereby the modular nature of the warehouse supports self-synchronization. Yet, the warehouse metaphor overlooks that different actors give different meanings to information at different points in time.

The second type of definition stresses the need for shared understanding and treats the COP as a way to 'achieve a sufficient level of shared information among the different organizations and jurisdictions participating in disaster operations at different locations, so all actors readily understand the constraints on each and the possible combinations of collaboration and support among them under a given set of conditions' (Comfort, 2007, p. 191). But also more generally, the 'common operational picture was specified as individuals knew who was doing what, who knew what; i.e., individuals had an accurate transactive memory' (Carley, 2002, p. 3). These definitions do stress the importance of shared understanding. The COP is not just an 'information warehouse' that supports self-synchronization but also a tool that supports its users to understand each other's needs and constraints during their collaboration. It recognizes that there are likely to be differences in mutual knowledge, belief, customs, and assumptions between different communities (Bechky, 2003) that cause conflicting interpretations of information that need to be made workable in order to organize a coherent response operation (Artman \& Wærn, 1999).
Although the second type of definition subscribes to the importance of developing a level of shared understanding, they still overlook the way in which shared understanding is reached by using the COP. To get a deeper understanding of the problem of information management, we need to open the black box to see how information sharing supports shared situational awareness.

Building a sufficient level of shared understanding to us is a sensemaking process in which organizational members (de/re)construct information influenced by their institutional background to find out what is going on in times of uncertainty (Weick, Sutcliffe, \& Obstfeld, 2005). This sensemaking process is based upon the knowledge responders have gained through (1) education, including training/exercises; (2) (war)storytelling; and (3) past experiences (Endsley, 1995; Taber, Plumb, \& Jolemore, 2008). Emergency responders have to constantly make sense of the situation because of the rapidly changing environment. During crisis management, not just individual sensemaking processes are important, but even more important is collective sensemaking, that is, how members from different communities try to generate shared understanding for coordinated action (Maitlis \& Sonenshein, 2010). Collective sensemaking in emergency management is about combining different cues, roles, scripts, and actions that arise from the actors' different institutional backgrounds (Weber \& Glynn, 2006) into a collaborative time critical response (Faraj \& Xiao, 2006).

Weak collective sensemaking is a major problem during crisis situations. For instance, Weick's (1993) analysis of the Mann Gulch fire shows that the lack of group level sensemaking processes resulted in poor decision-making and eventually in the loss of the lives of 13 fire fighters. Weick (1990) also made a similar analysis of poor sensemaking between the pilot crew of a KLM 747 moments before they crash into a Pan-Am 747 on the Los Rodeos airport in Tenerife. The co-pilot of the KLM flight stated 'we are now at take-off', while the tower and the Pan-Am crew interpreted this as being in the take-off position, the KLM crew had actually faulty initiated the take-off run.

While these sensemaking problems arose among actors with a similar institutional background, Dearstyne (2007) claims that sensemaking issues between actors with different institutional backgrounds lead to inter-organizational coordination problems. $\mathrm{He}$ shows that fire departments and police had trouble collaborating and sharing information during the World Trade Center attacks. Especially striking is his note that fire commanders on the ground experienced a lack of information about the burning towers, while police helicopter crews were filming them from above. These kinds of coordination problems between actors with 
different institutional backgrounds are central to largescale emergency response operations.

Coordinating between actors with different institutional backgrounds is described by Faraj and Xiao (2006) as a process of dialogic coordination. By engaging in dialogue, professionals are able to confront their different professional languages (jargon) through epistemic contestation and achieve joint sensemaking. During the process of collective sensemaking, emergency responders need to coordinate their actions temporarily and locally across their organizational boundaries, in which they must navigate their differences in norms, meanings, and interests with members from other organizations to achieve a shared goal (Kellogg, Orlikowski, \& Yates, 2006). This is especially challenging because in fast-paced environments, goals can be translated as such only in a limited amount of time as the emergency situation changes, and the goal becomes outdated. As a consequence, actors often 'forget' to share information because in their view information is no longer significant or is outdated. In this way, the perceived relevance of information is compromised at different points in time, resulting in a dynamic information sharing situation that is constantly in flux.

The actors' different institutional backgrounds and the time criticality show that information sharing cannot be reduced to gathering information from a warehouse. We propose a different perspective on the COP in which information sharing is about sensemaking that is better characterized by using the metaphor of a trading zone. In the literature, the trading zone is used as metaphor to describe the process of negotiation between actors from different communities in which they work out 'exchanges' 'in exquisite local detail, without global agreement' (Galison, 1997, p. 46). During the exchanges, actors must make sense and reach consensus about procedures of exchange in a mutually comprehensible language. In emergency management, trading is not just a metaphor because it sometimes literally means that actors have to reach an agreement on for instance the size of an evacuation zone. During this process, actors have to share their expertise to convince the other about the value of the alternatives. In this way, actors exchange ideas, learn from one another and make sense of each other's position and institutional background.Working out exchanges in this way is useful in conditions of uncertainty and change because the collaboration 'doesn't depend on shared ideas, interests, or norms, which are difficult to accomplish when time is short, meanings are divergent, and conditions are ambiguous' (Kellogg et al., 2006, p. 39; Vaughan, 1999).

In the literature, exchanges or trades often occur through the use of a boundary object (Hsiao, Tsai, \& Lee, 2012; Kellogg et al., 2006). Boundary objects are coordination mechanisms of representation, in which coordination is reached by disseminating information and providing a common referent as basis for aligning work between organizations (Okhuysen \& Bechky, 2009; Henderson, 1991). The COP can be regarded as a boundary object because constructing a COP is about sharing and constructing information about the response operation in such a way that it enables its users to continually redefine and mutually adjust their relationships. The COP provides a platform that allows experts to coordinate and negotiate their plurality of points of view through general procedures of exchange, without making their perspectives uniform or completely transparent to each other (Trompette \& Vinck, 2009; Hsiao et al., 2012). In turn, the trading zone perspective provides a way of analysing how this exchange process influences the actors' sensemaking efforts.

In summary, for us, the COP resembles not an 'information warehouse' but a form of materiality that facilitates the ongoing negotiation process that takes place in a 'trading zone', in which actors share and give meaning to information to synchronize their actions. How we analysed the data by applying the trading zone perspective to the sensemaking processes of the officers-incommand will be explained in the next section.

\section{Methodology and cases: a narrative analysis of the 'trading zone'}

Analysing the collective sensemaking processes (Weick, 1995 ) in the trading zone (Galison, 1997) requires a perspective in which the negotiation of meaning of information that is embedded in local contexts and in multiple realities becomes visible. Therefore, we adopted an ethnographic approach that allowed us to study the richness of the sensemaking process and grasp enough detail of the context in which these processes take place (Yanow \& Schwartz-Shea, 2006). This approach (Hammersley, 1995) is especially useful in unravelling the consequences of the actors' different institutional backgrounds as it enabled us to follow the real-life conversations and negotiations between the emergency responders.

We collected our data through visiting field command centre exercises of the first response organizations in different safety regions in the Netherlands, as part of our contract research into the information management practices during emergency response operations. First results of this research are published in Stuurman (2011) and Wolbers, Boersma, and de Heer (2012). We observed 10 exercises in a field command centre in which emergency officers in command of police, fire department, medical, and municipal authorities meet to share information and make decisions during an emergency. These consisted of both scenario driven and virtual (by means of computer simulations) exercises. The 10 incidents included a collision at sea, 
gas explosion, railroad accident, highway accident, hostage situation in a school and a helicopter crash on a water treatment plant. For each scenario, the officers practised delegating tasks through their teams by communicating with officers from other emergency services. Although the incidents were fictional, the officers were confronted with time pressure, information overload and, most important for our study, with professionals from other organizations than their own. We therefore feel that the exercises illustrate the situations in which responders get confronted during real incidents and offer valuable research data (Latiers \& Jacques, 2009). However, we must also mention the limits of using the data of exercises for analysis. Because the scenarios are removed from reality, there is limited recruitment delay, and participants are potentially protected from the ramifications of poor decision-making.

For this case material, we observed and recorded conversations in ten exercises, and afterwards eight officers were interviewed (see Stuurman, 2011) who participated in the same group in multiple exercises. The officers were selected based on their presence in the same observed set of exercises and were asked to reflect upon the collaboration, communication, and their actions and decisions. In the observations, we recorded the interaction, and in the interviews, the officers were provided with parts of these dialogues and situations. In doing so, we did not make an evaluation as such, but our focus was on finding patterns in the first responders' actions and interactions in the context of their professional routines. By reflecting on actions and storytelling, we were able to unravel their sensemaking efforts during the multi-organizational response.

Besides the interviews and observations, we analysed documents (including reports of the Inspectorate of Security and Justice, and the Dutch Safety Board) with the purpose of understanding the broader context in which the exercises were taking place. In addition, these reports were used to see whether our findings from the relative small sample of exercises are also reflected in real emergencies. Also, documents about procedures and responsibilities of the different emergency response agencies were analysed to inform our data analysis, as well as documents about the multiorganizational coordination structure. Although these procedures are not referred to directly in the article, they did inform our analysis by helping us to get background information on the technical terminology (such as evacuation standards or water screens) and help us judge whether interactions between officers in the trading zone were regarded as appropriate or not.

The data collection resulted in 70 pages of interview transcripts and 140 pages of observation transcripts. The fully transcribed exercises allowed us to reconstruct the interactions of the officers with each other and the COP chronologically. We analysed the transcriptions by adopting an interactional narrative analysis (Riessman, 2005). This type of narrative analysis zooms in on the dialogue between teller and listener to analyse the dialogue as a process of co-construction, where teller and listener create meaning collaboratively (Riessman, 2005). The transcripts from the interviews and the data from the observations were combined with the help of the data analysis tool MaxQDA to inform this analysis and to guide data reduction.

Analysing narratives enabled us to zoom into the underlying cues, roles, scripts, and recurrent action that arise from the different institutional context of the emergency responders, as well as their organizational values (Gabriel, 2000). Through their narratives, actors implicitly and sometimes explicitly negotiate about their interpretations and actions (Czarniawska, 2004). Implicit problem conceptualizations are made tangible by signalling potential problems, clarifying misunderstandings and exchanging information (Putnam, 1994). We used these cues to inform our analysis and identify challenges in sensemaking and negotiation between officers. With the help of (lexical) search in MaxQDA and close reading, we were able to identify interesting narratives.

We will present our data by focusing on three more in-depth narratives that occurred during the exercises to allow for enough detail in the descriptions. These narratives were selected based on the richness of the interactions between the actors that illustrated the negotiations of interpretations in the trading zone most clearly. In addition, these three scenarios were chosen because they are illustrations of how (implicit) contestations had immediate impact on action. It shows that the trading zone perspective is not just a scholarly, analytical perspective: problems with negotiation have a direct impact on the actual response operation.

\section{Findings}

\subsection{Setting the scene: cross-boundary coordination between Dutch emergency management organizations}

The Dutch emergency management system consists of an emergent structure that can be scaled up after the emergency response centre (ERC) alerts the police, fire and/or medical services. The ERC follows a set of pre-defined protocols to call the officers-in-command from these organizations to the incident scene. Each officer is responsible for commanding his or her own operational units on scene. Additionally, the officer-incommand is responsible for taking care of the interorganizational coordination with other emergency services. To support this responsibility, a mobile field command centre is installed on scene and staffed with 
the officers-in-command and the field commander. The core staff consists of the field commander, police officer, fire officer, medical officer, and municipal officer. If the nature of the incident requires additional expertise, other liaison officers of, for example, the Railroads or Waterworks can be added to the team.

In the Netherlands, exercises have the specific aim to improve the quality of multidisciplinary collaboration. Evaluations of incidents have shown that 'in the heat of the moment employees temporarily lose sight of the interests of the other emergency services' (Scholtens, 2008 , p. 200). As such, multidisciplinary collaboration should be effectuated at a much earlier stage, and exercises are aimed at effectuating these, both disciplinary and multidisciplinary, work practices (Bharosa et al., 2010).

In the following cases, we will study the officers-incommand and the field commander that operate in the mobile field command centre. We will analyse the conversations between the officers-in-command in the field command centre. We regard the process of constructing the COP as a trading zone in which the different interpretations and narratives about the incident are co-created and negotiated.

\section{2. 'Trading zones': constructing the COP during emergency response operations}

4.2.1. Case 1: 'Is one hundred meters far enough?' Discussions about safety during an explosion

Several residents called 911: they smelled gas in the direct environment of a flat building. Moments earlier, a suicidal man in the house has opened the gas valve on his oven and tried to trigger an explosion. The dispatcher in the emergency room sends a fire engine to the scene to investigate the threat. On the spot, the fire fighters indeed measure a high concentration of gas in the building. They decided to scale up and call for the assistance of the fire, police, and medical officer. Next according to the procedures of the Dutch emergency response $-\mathrm{a}$ field command centre is created at the location of the incident. Soon after the officers of the police, fire brigade, and medical teams arrived at the scene, they organize a brief meeting. A possible evacuation of the apartment and the security of the first responders are central elements in the discussion.

\subsubsection{Negotiations during the field command meeting}

In the first meeting between the officers, we heard a discussion about the size of the area that has to be evacuated to protect the first responders and the bystanders:

Police officer: 'I think we still need to withdraw from the scene a bit further. Five hundred meters ...'
Fire officer: 'Five hundred meters evacuation zone ...

Police officer: 'Okay then, at five hundred meters. And for our people: safety? Are we .... will you go ... we go in? Will there be gas in there?'

Fire officer: 'We cannot measure the amount of gas, so we do not know how safe it is.'

Police officer: 'So you will evacuate the building as well?'

Fire officer: 'Yes.'

Police officer: 'So then we will only set up the road blocks?'

Fire officer: 'Yes and we will transfer the people who come out of the building to you.'

Medical officer: 'There are some people waiting by the ambulance. I understand that five hundred meters away from the building is safe?'

Fire officer: 'Yes, we now take those five hundred meters for safety.'

\section{Medical officer: 'Fine.'}

Central in this conversation is the safety of the first responders. The notion that 'we cannot have more victims (i.e., wounded rescue workers)' is central in their discussion. It is quite difficult, however, to estimate the risk of the incident and the size of the area that will be affected by a possible explosion. Because the fire fighters - the experts in such situations - cannot give closure about the risk, the police and other first responders decide to back off. Interestingly, the officers from the different response organizations use 'we' in their conversations indicating that they talk about a problem that will affect all of the rescue workers regardless their organizational background.

One important issue the officers have to negotiate about is the size of the area that has to be protected so that no one without protected clothing (including citizens and rescue workers) can enter the scene. It is quite difficult, however, to make that decision as the fire fighters can only estimate the risk - an explosion in the apartment is still one of the possibilities at the time of the first conversation. During the next meeting between the officers, we witnessed the following conversation:

Field commander: 'We have to sit down here a bit longer, because we still have no overall picture of 
the area and the distance of five hundred meters. There is not only a construction site, a separate building and a school, but there is a lot more. What are we going to do about it?'

... a discussion between the different officers follows and the Field Commander makes a short résumé ....:

'Are we saying that we need to use the sirens in the area? Windows and doors closed? Or do we say that the risk is not big enough yet? Because we have to secure that whole area of five hundred meters ... that is a very big circle.'

Fire officer: 'I won't take a risk; if the building explodes and collapses, parts will fly everywhere... I have seen that once in Amsterdam, the pieces reach pretty far. And you cannot take any chances. It is certainly not advisable in this situation to protect an area less than five hundred meters.'

Field commander: 'Okay, so basically you are saying, let the sirens go off?'

Municipal officer: 'I do think we need to look closely at the communication ... And we also have the railroad. So there is also a little ...'

Field commander: 'There is also a railroad?'

Municipal officer: 'Yes. It is within five hundred meters.'

\subsubsection{Participant reflections on the negotiations}

It becomes clear in this conversation that the officers have a dilemma here: the fire officer does not want to take any risk and advices to secure the area within the radius of $500 \mathrm{~m}$. As the fire brigade is in charge of the evacuation within the zone, their advice is taken very seriously by the other first responders. However, it is quite impossible for the municipality and the police to implement the advice since that can only be done against high costs (literally): it is almost impossible to control an area that big. The police officer who was at the meeting explained us his feeling he had during the conversation:

'I would like to create a 500 meter radius around the area and I want no traffic coming through there. Get it done! Well, it really doesn't work that way. I mean, the problem is that it assumes that you are in control. But then you hear that there are many side roads that we cannot take care of, because they are in an area that we cannot reach by (police) car. Also, we learn that we have not enough people. This information all comes in and tends to overrule all the other information.'
A closer look at the use of language in the narratives reveals that the professionals start to use ' $l$ ' instead of 'we', indicating that they revert to their personal and/or own professional framework. In either case, this perspective is informed by their proficiency (education and/or experience). In this case, the officer of the fire brigade is referring to an earlier experience - not uncommon in such situations of uncertainty (e.g., Boje, 1991). Towards the end of the meeting, however, it becomes clear during the negotiation that the concerns of the other officers challenge the decision of keeping a $500 \mathrm{~m}$ evacuation radius. The officers discover that the situation in Amsterdam, to which the fire officer referred, was in a much more open area. An explosion in such a situation would mean lots of flying pieces of material. However, in the area that would be affected by the explosion at hand are a lot of buildings, meaning that there are a lot of buffers in the area that will prevent material from flying around. The fire officer and the police officer give two contrasting perspectives on dealing with this threat. The fire officer explains his point of view in an interview.

'In first instance, a safe distance of 500 meters. A gas leakage. I have seen them in Amsterdam and on television. I don't know what's leaking and how big it is. I will take a large safety precaution of 500 meters, which we can reduce to 100 or 200 meters later on. But if I don't have enough information, then I will choose for safety, instead of moving up to 100 meters. We might see a chain reaction or explosion. I might have taken too much safety, but I'm always of making sure first.'

In a similar exercise a day later, a different police officer, who is also a team leader and expert on explosives and safety, estimates that an evacuation area of $500 \mathrm{~m}$ is way too large for a gas explosion. He states that a gas explosion only damages an area around 25-50 m, so a distance of $100 \mathrm{~m}$ should be enough. In this exercise, a distance of $100 \mathrm{~m}$ is chosen, and this way the police do not get into trouble with the large evacuation area.

'Well, this is a gas explosion. It will damage an area of 25-50 meters. But you must also check what's in front of the building. Is it an open space, or are there all kind of structures in the way? If there are buildings in the blast radius they will keep the explosion from going further. On the end of the explosion a window might shatter, but that's it. It will not go further.'

At first glance, this can be seen as a technical discussion about the effects of an explosion, but the negotiation is vital for the different professionals to come to an agreement about the actions that have to be 
undertaken. The interpretation of the risk and the actions, however, differs from the various professional backgrounds. The officers used the field command centre meeting as a trading zone to develop a common understanding of the situation.

However, the professionals did not reach closure at this time. The different interpretations of the officers are not discussed in detail in the field command meetings. It did not become clear enough in what way the narratives are at odds and how they are complicating the response operation of other disciplines. The second narrative is mainly held in the personal ' $l$ ' framework, which gives room for different opinions, but does not show why some decisions are problematic for others.

\subsubsection{Case 2: 'Can we go on board?' Discussions about} hazardous materials on board of a ship

A captain on the ship Stavria reports to the coast guard that his ship has an engine failure and that he has run aground. Not soon after this, a fishing boat with 75 tourists on board reports that it had to avoid a collision with the Stavria and has also run aground. As a result of the sudden evasive manoeuvre, some passengers got injured; it is unclear how many and how serious. First ambulance crews on scene board a coast guard's ship to get to the incident scene. They enter the fishing boat to make an initial estimation of the amount of wounded passengers. Once on board, it appears that there are dozens of people injured.

\subsubsection{Negotiations during the field command meeting}

During the first meeting of the officers in the field command centre, a liaison officer of the Dutch Waterworks joins them with the announcement that the Stavria is loaded with natural gas condensate, which has partially escaped. The highly toxic cloud of gas condensate threatens the passengers of the fishing boat. The natural gas condensate requires the officers to discuss the dangers for their units and the passengers:

Field commander: 'There is some additional information for the common operational picture ... Let's see ... Is it really urgent?'

Waterworks officer: 'Yes, the Stavria is loaded with natural gas condensate.'

Field commander: 'Jeez.'

Waterworks officer: 'And it has escaped. Several passengers on board of the Stavria became ill. And they have to be treated, they are in danger. But my units have to stay upwind, at a safe distance from the Stavria.'
Field commander: 'What is the direction of the wind at the moment?'

Waterworks officer: 'South-east. And that means that the fishing boat is right in the midst of the smoke ...'

Medical officer: 'So the people cannot be disembarked?'

\section{Waterworks officer: 'No.'}

Outside of the field command centre, the fire officer and the officer of the Dutch Waterworks have an informal conversation.

Fire officer: ' $\ldots$ this situation requires a water screen. Do you have a fire boat at your disposal that can take care of this?'

Waterworks officer: 'Yes ... yes, we have such a ship ... yes, we can make that screen.'

The announcement of the natural gas condensate disturbs the consultation-round in the field command meetings. The field commander immediately asks for more information about the wind direction to estimate the size of the threat. At this moment, the information forces the officers to be flexible and immediately start thinking of alternative solutions to protect not only the victims, but also the emergency crews responding to the incident. Meanwhile, ambulance crews have boarded the fishing boat to provide first aid and are now also under threat of the gas condensate.

\subsubsection{Participant reflections on the negotiations}

For the fire officer it is really important to understand the risk of the gas leak and how the danger can be reduced. This is, for a great deal, a technical problem for which he has the expert knowledge (as part of his institutional background). In an interview with us he argues:

'We are talking about natural gas condensate. I want to know: How is it stored? Is it condensed? Did it leak? At that moment this was not clear. So you ask: how much expertise do we have? And you can close the leak? But at the same time: I did not know how big the leak was and what the crew on the ship could do, whether they are trained to do this or not ...We have a fire boat with a large water cannon. Well, let me bring that to the scene. I order a water screen to be put in place, so they are safe. For the rest ... that ship has no emergency. Then we have enough time.' 
However, the medical officer has other concerns because her ambulance crews are on the fishing boat. She wants to act as quickly as possible because both her people as well as the victims have to abandon the ships as soon as possible. Normally, the medical team distances itself from the scene if there is any danger to personnel: safety first.

'My people are on board of the ship. Only on the ship of the Dutch Waterworks they seem to be safe and from there they can work. We could not give any facts on the situation on board of the Stavria, since we have not been there. Then we got information about the ship, the wind, and so on: what is going on!? And then that misery that appeared in the field command center about the natural gas condensate ... At that time we have a major safety issue for our own crews!! We have to save the victims, but because of the safety issue we couldn't do that. So we know that there will be more victims, because that fishing boat with eighteen people on board was still in the midst of the natural gas condensate.'

At this moment in the meeting, the officers have a different perception about the priorities, and as a result, about the amount of time that is left. These different perceptions are reflected in the way in which the officers engage in the negotiation. In contrast to the perception of the fire officer, who is convinced that placing a water screen buys him all the time he needs, the medical officer interprets the situation as much more threatening. Her narrative addresses the need to get the ambulance crews and victims out from the unsafe situation rapidly. Next to the rescue operation on the ship, the medical officer also anticipates a logistical problem when all the victims are brought on shore at once and need to be transported to the hospital. It is noteworthy that the discussions in the field command meeting focus solely on the rescue operations, but there is little attention for the care and transportation of the victims. This, however, is crucial information for the medical officer. While the rescue and safety operations are treated as a multidisciplinary problem (i.e., all the disciplines have to be involved in the action), the further treatment of the victims as soon as they are ashore is seen as a problem only for the medical team.

'At the moment we have the water screen in place, we can only do one thing and that is rescue the victims from the ship as soon as possible. We cannot perform a full triage on all the victims and see who needs to go off the ship first. We even cannot use our normal work practice, that is stabilizing victims first and create a prioritization. I need all available coastguard and life guards to get everybody off the ship at once. Because at the moment the water screen ceases to exist we find ourselves in a potentially unsafe situation. I need a lot of help from other partners to do this, so a lot of ships, people, and hands. That also means that if we get to the harbour I get at least 60 victims on shore, that will be an utter chaos. I need all the help I can get to solve that problem.'

The reflections of the medical officer show that organizing a coherent triage and transportation of mass casualty scenarios is a daunting task (e.g., see Tierney, 1985; Koenig \& Schultz, 1994). She will need the help of all the available emergency agencies to structure this process. Yet, the fire crews themselves are busy dealing with keeping the water screens operational and taking care of the gas leakage on the Stavaria. In the field command meeting, the interests of medical and fire operations must be negotiated and balanced to organize a coherent response operation. This involves both getting the gas leakage under control and providing medical care and transportation for victims. The exercise example shows that organizing such a coherent response operation requires the officers to negotiate their interests, but also to value the mutual dependency on safety standards and operational capability with other emergency agencies.

\subsubsection{Case 3: 'How old are the kids?' Discussions about victims of a shooting incident}

A man with a gun entered a high school and started shooting. He injured a couple of students; it is unknown how many. The man took some children and the teacher hostage in the chemistry classroom. In the chaotic situation that follows, one of the children switched on a smoke detector causing a fire alarm. The emergency response room receives the alarm and sends a fire engine to the school. At the same time, the concierge called 911. Next, the hostage-taker releases a girl with a letter addressed to the management of the school. The girl is able to tell that the teacher is strapped to a chair and that the hostage-taker threatens to set fire to the room. After the first responders arrived, the officers of the different disciplines gather in the field command centre and they discuss a possible raid by the police SWAT (Special Weapons And Tactics) team. The medical officer wants to know more about the victims, so he can arrange enough ambulances and inform the hospitals.

\subsubsection{Negotiations in the field command meeting}

The first conversation between the officers of the different organizations unfolds: 
Medical officer: 'Okay. How old are the students?'

Police officer: 'I have no ... no idea.'

Field commander: 'High school students.'

Medical officer: 'But twelve or seventeen years old makes a lot of difference to me...'

Field commander: 'Uhm ... there are twentyseven pupils in total. Is that the only class that is still present in the school building? The rest of the building is evacuated?'

Fire officer: 'Yes, I think so, but that is still an assumption.'

Field commander: 'Okay. I would ask you then to verify if that assumption is correct or not. This is an action.'

Police officer: 'Alright, that is clear. The concierge has removed all of the other kids and he only missed these children. So that is for sure.'

Field commander: 'Okay. In any case, you know that you have to take care of twenty-seven students who are still in the building.'

At first glance, this conversation does not seem to involve a direct negotiation of interest. Yet, the lack of a negotiation between the police and medical officer about the age of the students leads to a crucial challenge in the response operation. In this conversation, we see the medical officer asking for the exact age of the children - important information for his units. However, the dominant narrative in the field command centre is about the number of children that are still in the building. For the others, at this time more dominant disciplines, this information is vital for their actions.

\subsubsection{Participant reflections on the negotiations}

The medical officer is a bit disappointed about this attitude. He argued:

'For us this information is extremely important to have... It really matters if the children are eleven or seventeen years old, in order for us to be prepared. In particular, it has an impact for the care in the hospitals. A hospital can easily accommodate five seventeen year olds, but five eleven year olds, that is another story. An eleven-year cannot be treated as an adult with medication and injections and so on ... So therefore, for us the age of the children is quite important. And I really did not get a good answer to my question in this respect, no.'
In order to understand this problem, it is good to realize that the medical officer is always representing a network of organizations, including hospitals, ambulance services and medical doctors, and so on. These organizations have their own rules and procedures implemented. For example, for the hospitals the children's age is crucial information: a paediatrician must be available to take care of under-age kids.

This aspect of the medical response operation is not understood by other professionals; at least, it is hard for them to understand how this affects the work of the medical team's officer at the location of the incident. The medical officer takes the decision - by himself - to not further discuss this point, but to let the actions of the other rescue organizations prevail. Although this might be a reasonable choice to keep initial speed in decision-making, failing to get the children's age might eventually backfire since it can lead to serious problems in transporting a yet unknown, but possible large amount of under-age victims to paediatric hospitals later on.

\section{Discussion and conclusion}

In this article, we have analysed how emergency responders interpret information by using the metaphor of the trading zone and have shown how this affects their collective sensemaking. In the trading zone, the officers reach coordination by telling each other stories about their actions and perceptions (e.g., of risk and the evolution of an incident). The cases illustrate the way in which information is traded, based on its contextualized meaning to different professional communities, during the negotiations between officers in the field command centre. In response to an explosion with asbestos, a collision on sea, and a hostage situation in a school, it becomes clear that not just the information itself is important for coordination, but particularly the way in which information is interpreted and subsequently guides the operations of the emergency responders. We have shown that information is not univocal, but incorporates different professional languages and is often incomplete as the situation it represents is in constant flux. In addition, information must be made actionable to its different users to support the inter-organizational coordination efforts in emergency response. Therefore, information management during emergency response operations is about interpreting information and negotiating its relevance for different professions. In our analysis, we have encountered mainly two problems with the interpretation and negotiation of information between officers in the trading zone.

First, in the trading zone, there can be a limited understanding of what consequences information has 
for the action and needs of other professionals. The officers identify each other's specialized knowledge and roles differently throughout the incident response operation because the officers can represent different specialized clusters of organizations during the response operation. This occurs, for instance, in case 3 when the medical officer resembles a wide network of medical care institutions of which, especially the different back offices, are not known to the other officers. Consequently, the other officers do not identify paediatric care as an important agency. This example shows that the relevance of information to others is coupled to the identification and understanding of different roles, thus a problem of referral that requires knowledge about functions.

Second, in the trading zone, a dominant narrative can develop that does not allow different interpretations of information to become visible. In their dialogue, the officers are confronted with different professional languages, that is, knowledge of each other's specialized jargon, roles, and norms. These are sometimes visible (i.e., the fire fighters refer to specific procedures) but also include non-visible elements, such as standards of work practice and preferences about priorities. For instance, the efficacy of a water screen is contested in case 2. These kinds of problems show that different meanings are attributed to information in action, calling for a way to trigger reflection on the origin of these meanings.

We do recognize the limitations of our relative small set of narratives for supporting this claim. Still, we believe that these examples can be illustrative for social dynamics seen during negotiations in real-life response scenarios. We found evidence of similar negotiation issues in evaluation reports on actual incidents that support the trustworthiness of our claims. For instance, during a large headland fire on the 'Strabrechtse Heide' in 2010, police and fire officers had trouble with negotiating about the necessity and timing of installing roadblocks on a smoke affected highway (Inspectorate of Security and Justice, 2011a). Also, during the response to the chemical fire in the Dutch city Moerdijk, privatized fire crews and crews from different regions had trouble negotiating the amount of fire extinguishing water necessary for balancing between controlling the fire and preventing environmental damage (Inspectorate of Security and Justice, 2011b). Finally, the medical response to the Turkish airlines crash in 2009 shows negotiations about the need for Mobile Trauma Teams between medical officers and the emergency response centres (Dutch Safety Board, 2010). Requests for mobile trauma teams were declined in the first half hour of the incident due to incorrect priorities. While these cases (taken from investigation reports) illustrate negotiation practices at a higher level of abstraction, the cases we studied gave us the opportunity to zoom in on similar negotiations in detail.

\subsection{Actionable knowledge and reflexivity}

The two information management challenges about understanding the consequences of information and the existence of a dominant narrative show that making information widely available is not enough for effective crisis management. It is the development of shared understanding, based on information exchange, which is essential for the coordination between multiple organizations. As a result, the 'warehouse metaphor' is not appropriate: our proposed metaphor of the 'trading zone' is more adequate. By putting the negotiation of information central, the metaphor of the trading zone reveals that information sharing inhibits knowledge that needs to be put into action and requires reflexivity about its meaning to different groups. Therefore, we will discuss two concepts that take this inference further: making information usable by developing actionable knowledge and enhancing shared understanding by supporting reflexivity-in-action.

First, actionable knowledge is knowledge that "leads to immediate progress on a current task or assignment' (Cross \& Sproull, 2004, p. 446). Developing actionable knowledge can support the connection between information itself and the way information is seen as input for action. Since in the trading zone it appears that there is a limited understanding of what consequences information has for the actions in different organizations, developing actionable knowledge can help build this understanding. In detail, five components of actionable knowledge can be identified: solutions (both know-what and know-how), referrals to people or databases, problem reformulation, validation, and legitimization (Cross \& Sproull, 2004). Making knowledge actionable by engaging with these components allows one to collaboratively create a shared understanding by addressing the implications of shared information.

Secondly, enhancing reflexivity is a crucial condition to address the problem of dominant narratives during information sharing in the trading zone. Reflexivity and knowing-in-action (Schön, 1983) can make differences in the interpretation explicit. Knowing-in-action is about not only including one perspective in a story, but to include the other professional perspectives as well. Reflexivity allows the professional to redirect his or her decisions without being hindered by professional boundaries. This, of course, is a learning process that (literally) needs training and education (Schön, 1987) to see the constraining and enabling characteristics of multi-organizational work. Reflection, as Schön (1983) has argued, starts with the recognition of the problem and continues with the development of affective responses and empathy. 
Therefore, a multi-organizational emergency response operation involves asking and answering the questions (Yanow, 1997): What do I do? Why do I do it? What does it mean for me, as a professional and for the other professionals I work with and for? In this way, emergency responders can become more sensible of each other's sensemaking processes and the meaning of information for action. Reflexivity-in-action and actionable knowledge are two additional concepts that we address to unpack the process of negotiating information in the trading zone. Still, taking this scope on information sharing and collective sensemaking might leave out other dynamics.

\subsection{Further research}

Further research towards other mechanisms in the trading zone is required to contribute to a broader understand of information sharing in crisis and disaster management. Examples of other mechanisms in the trading zone that might be unpacked are cognitive, such as mental models (Majchrzak, Jarvenpaa, \& Hollingshead, 2007); social, such as groupthink (Walle \& Turoff, 2008); power, such as orchestrations of interests (Kellogg et al., 2006); and linguistic, such as the creolization of a mutually comprehensible language to support negotiation in the trading zone (Galison, 1997). Besides attention for other mechanisms in the trading zone, further research might also touch upon the idea that multiple trading zones can exist at different levels of the disaster response organization. As a consequence of the modular nature of the up-scaling process during emergency response, different teams at different locations need to coordinate their actions. In this way, different, possibly overlapping, trading zones exist that might employ different kind of 'trades', such as more strategic or political sensitive decision-making processes.

\subsection{Implications for practice}

Next to the implications for theory, the perspective of sensemaking in the trading zone also houses tangible implications for practice. The narratives in the exercises illustrate that it is important to allow time for the stories that contain different interpretations of the officers. Field command meetings are often characterized by quick decision-making based on the separate professional frameworks of the officers. In effect, their different interpretations of the same information do not always show. Narratives are not completely told, or there is not enough recognition of other interpretations or work practices. Yet, it is important to share narratives in field command meetings. This claim appears to be at odds with the goal to keep field command meetings short and decisive so that officers can return 'to the field'. However, in our empirical study, we found that problems will appear later in the response operation if shared sensemaking is neglected. So, in the field command meetings, moments of reflection must be created to overcome differences in interpretation.

Learning how to become reflexive-in-action requires practitioners to rethink operational training and education. Training sessions might explicitly focus on telling narratives about bottlenecks in the response operation to make interpretations of information from different professional frameworks explicit. We witnessed that the focus of training sessions often lies on increasing the speed of decision-making. Our recommendation, however, is to find a balance between promptness and the quality of decision-making that incorporates multiple perspectives. To allow this, officers must bide the time for reflexivity. We recognize that balancing between speed of decision-making and reflexivity is difficult. Still, it is important that team members listen and learn from each other's perspectives and allow time to think 'out of the box'. In the end, making betterinformed decisions avoids problems later on in the response operation and can only save time.

In this article, we have illustrated that the perspective of the trading zone offers a new approach to study information management that puts collective sensemaking to the fore and offers lessons both for theory and for practice. We feel that it is time to employ such a perspective to increase our understanding of the complex information sharing and meaningmaking processes in emergency management. The trading zone perspective is a crucial and missing perspective, which is needed to reflect upon the complex problems in emergency response. It is necessary to employ multiple perspectives to understand these complex phenomena. The trading zone perspective can be combined with other perspectives (e.g., decisionmaking and learning) to better understand and support the multifaceted social processes behind the challenging task of information management during emergency response operations.

\section{Note}

1. The quotes are translated from Dutch language to English by both authors to check for consistency in the translation process.

\section{References}

Artman, H. and Wærn, Y. (1999), 'Distributed Cognition in an Emergency Co-ordination Center', Cognition, Technology \& Work, Volume 1, Number 4, pp. 237-246.

Bechky, B.A. (2003), 'Sharing Meaning across Occupational Communities: The Transformation of Understanding on a Production Floor', Organization Science, Volume 14, Number 3, pp. 312-330. 
Bharosa, N., Lee, J. and Janssen, M. (2010), 'Challenges and Obstacles in Sharing and Coordinating Information during Multi-Agency Disaster Response: Propositions from Field Exercises', Information Systems Frontiers, Volume 12, Number 1, pp. 49-65.

Boersma, K., Wagenaar, P. and Wolbers, J. (2012), 'Negotiating the Trading Zone. Creating a Shared Information Infrastructure in the Dutch Public Safety Sector', Journal of Homeland Security and Emergency Management, Volume 9, Number 2, pp. 1-25.

Boje, D.M. (1991),'The Storytelling Organization:A Study of Story Performance in an Office-Supply Firm', Administrative Science Quarterly, Volume 36, Number 1, pp. 106-126.

Carley, K.M. (2002), Inhibiting Adaptation, DTIC Document.

Clark, H.H. and Brennan, S.E. (1991), 'Grounding in Communication', Perspectives on Socially Shared Cognition, Volume 13, pp. 127-149.

Comfort, L.K. (2007), 'Crisis Management in Hindsight: Cognition, Communication, Coordination, and Control', Public Administration Review, Volume 67, Number s1, pp. 189-197.

Comfort, L.K. and Kapucu, N. (2006), 'Inter-Organizational Coordination in Extreme Events: The World Trade Center Attacks, September 11, 2001', National Hazards, Volume 39, Number 2, pp. 309-327.

Copeland, J. (2008), Emergency Response: Unity of Effort through a Common Operational Picture, DTIC Document.

Cross, R. and Sproull, L. (2004), 'More than an Answer: Information Relationships for Actionable Knowledge', Organization Science, Volume 15, Number 4, Pp. 446-462.

Czarniawska, B. (2004), 'On Time, Space, and Action Nets', Organization, Volume 11, Number 6, pp. 773-791.

Davenport, T.H. (1993), Process Innovation: Reengineering Work through Information Technology, Harvard Business Press, Boston, MA.

Dearstyne, B. (2007), 'The FDNY on 9/11: Information and Decision Making in Crisis', Government Information Quarterly, Volume 24, Number 1, Pp. 2946.

Donahue, A.K. and Tuohy, R.V. (2006), 'Lessons We Don't Learn:A Study of the Lessons of Disasters, Why We Repeat Them, and How We Can Learn Them', Homeland Security Affairs, Volume 2, Number 2, pp. 1-28.

Dutch Safety Board (2010), Hulpverlening na vliegtuigongeval Turkish Airlines, Haarlemmermeer. 25 Februari 2009. Den Haag.

Endsley, M.R. (1995), 'Toward a Theory of Situation Awareness in Dynamic Systems', Human Factors: The Journal of the Human Factors and Ergonomics Society, Volume 37, Number 1, pp. 32-64.

Faraj, S. and Xiao, Y. (2006), 'Coordination in Fast-Response Organizations', Management Science, Volume 52, Number 8, pp. 1155-1169.

FEMA (2009), National Incident Management System (NIMS) Student Manual IS-700.A. Communication and Information Management.

Gabriel, Y. (2000), Storytelling in Organizations: Facts, Fictions, and Fantasies, Oxford University Press, Oxford, NC.

Galison, P. (1997), Image and Logic: A Material Culture of Microphysics, The University of Chicago Press, Chicago, IL.

Hammersley, M. (1995), Ethnography: Principles in Practice, Routledge, NY.

Henderson, K. (1991), 'Flexible Sketches and Inflexible Data Bases: Visual Communication, Conscription Devices, and Boundary Objects in Design Engineering', Science, Technology \& Human Values, Volume 16, Number 4, pp. 448-473.

Houghton, P., Leedom, D.K. and Miles, J. (2002), Command Information Infrastructure and Sense-Making. Paper presented at the 7th International Command and Control Research and Technology Symposium, September, Quebec City, Canada.

Hsiao, R.L., Tsai, D.H. and Lee, C.F. (2012), 'Collaborative Knowing: The Adaptive Nature of Cross-Boundary Spanning', Journal of Management Studies, Volume 49, Number 3, pp. 463-491.

Inspectorate of Security and Justice (2011a), Brand Strabrechtse Heide. Deel 1 De Hoofdstructuur van de Rampenbestrijding. IOOV, Den Haag.

Inspectorate of Security and Justice (2011b), Brand Chemie-Pack Moerdijk. IOOV, Den Haag.

Kapucu, N. (2006), 'Interagency Communication Networks during Emergencies: Boundary Spanners in Multiagency Coordination', The American Review of Public Administration, Volume 36, Number 2, pp. 207-225.

Kellogg, K., Orlikowski, W. and Yates, J. (2006), 'Life in the Trading Zone: Structuring Coordination across Boundaries in Postbureaucratic Organizations', Organization Science, Volume 17, Number 1, Pp. 2244.

Koenig, K.L. and Schultz, C.H. (1994), 'Disaster Medicine: Advances in Local Catastrophic Disaster Response', Academic Emergency Medicine, Volume 1, Number 2, pp. 133-136.
Latiers, M. and Jacques, J.M. (2009), 'Emergency and Crisis Exercises: Methodology for Understanding Safety Dimensions', International Journal of Emergency Management, Volume 6, Number 1, pp. 73-84.

Leedom, D.K. (2003), 'Functional Analysis of the Next Generation Common Operating Picture', Analysis, Volume 69, Number 2, pp. 149-163.

Maitlis, S. and Sonenshein, S. (2010), 'Sensemaking in Crisis and Change: Inspiration and Insights from Weick (1988)', Journal of Management Studies, Volume 47, Number 3, pp. 551-580.

Majchrzak, A., Jarvenpaa, S.L. and Hollingshead, A.B. (2007),'Coordinating Expertise among Emergent Groups Responding to Disasters', Organization Studies, Volume 18, Number 1, pp. 147-161.

Manzi, C., Powers, M.J. and Zetterlund, K. (2002), Critical Information Flows in the Alfred P. Murrah Building Bombing: A Case Study, Chemical and Biological Arms Control Institute, Washington, D.C..

Marincioni, F. (2007), 'Information Technologies and the Sharing of Disaster Knowledge: The Critical Role of Professional Culture', Disasters, Volume 31, Number 4, pp. 459-476.

Meissner, A., Luckenbach, T., Risse, T., Kirste, T. and Kirchner, H. (2002), Design Challenges for an Integrated Disaster Management Communication and Information System. Paper presented at the First IEEE Workshop on Disaster Recovery Networks (DIREN 2002).

Morris, J.C., Morris, E.D. and Jones, D.M. (2007), 'Reaching for the Philosophers Stone: Contigent Coordination and the Military Response to Hurricane Katrina', Public Administration Review, Volume 67, Number s1, Pp. 94106.

Moynihan, D.P. (2008), 'Combining Structural Forms in the Search for Policy Tools: Incident Command Systems in US Crisis Management', Governance, Volume 21, Number 2, pp. 205-229.

Moynihan, D.P. (2009), 'The Network Governance of Crisis Response: Case Studies of Incident Command Systems', Journal of Public Administration Research and Theory, Volume 19, Number 4, pp. 895-915.

Netten, N. and Van Someren, M. (2011), 'Improving Communication in Crisis Management by Evaluating the Relevance of Messages', Journal of Contingencies and Crisis Management, Volume 19, Number 2, pp. 75-85.

Okhuysen, G.A. and Bechky, B.A. (2009), 'Coordination in Organizations: An Integrative Perspective', Academy of Management Annals, Volume 3, Number 1, Pp. 463-502.

Putnam, L.L. (1994), 'Productive Conflict: Negotiation as Implicit Coordination', International Journal of Conflict Management, Volume 5, Number 3, PP. 284-298.

Quarantelli, E.L. (1997), 'Problematical Aspects of the Information/ Communication Revolution for Disaster Planning and Research: Ten Non-Technical Issues and Questions', Disaster Prevention and Management, Volume 6, Number 2, pp. 94-106.

Rake, E.L. and Nja, O. (2009), 'Perceptions and Performances of Experienced Incident Commanders', Journal of Risk Research, Volume 12, Number 5, PP. 665-685.

Riessman, C.K. (2005), 'Narrative Analysis', in Kelly, N., Horrocks, C., Milnes, K., Roberts, B. and Robinson, D. (eds.), Narrative, Memory Everyday Live, University of Huddersfield, Huddersfield, pp. 1-7.

Scholtens, A. (2008), 'Controlled Collaboration in Disaster and Crisis Management in the Netherlands, History and Practice of an Overestimated and Underestimated Concept', Journal of Contingencies and Crisis Management, Volume 16, Number 4, pp. 195-207.

Schön, D.A. (1983), The Reflective Practitioner: How Professionals Think in Action, Basic Books, New York.

Schön, D.A. (1987), Educating the Reflective Practitioner, Jossey-Bass, San Francisco.

Schooley, B.L. and Horan, T.A. (2007), 'Towards End-to-End Government Performance Management: Case Study of Interorganizational Information Integration in Emergency Medical Services (EMS)', Government Information Quarterly, Volume 24, Number 4, pp. 755-784.

Stuurman, M. (2011), Crisis Management \& Actionable Knowledge. Master thesis, VU Amsterdam. http://www.ubvu.vu.nl/pub/fulltext/scripties/26_1963538.pdf (accessed 18 September 2013).

Taber, N., Plumb, D. and Jolemore, S. (2008), 'Grey Areas and Organized Chaos in Emergency Response', Journal of Workplace Learning, Volume 20, Number 4, pp. 272-285.

Tierney, K.J. (1985), 'Emergency Medical Preparedness and Response in Disasters: The Need for Interorganizational Coordination', Public Administration Review, Volume 45, Special Issue, pp. 77-84.

Trompette, P. and Vinck, D. (2009), 'Revisiting the Notion of Boundary Object', Revue d'Anthropologie des Connaissances, Volume 3, Number 1, PP. $3-25$. 
Vaughan, D. (1999), 'The Role of Organization in the Production of TechnoScientific Knowledge', Social Studies of Science, Volume 29, Number 6, Pp. 913-943.

Walle, B. and Turoff, M. (2008), 'Decision Support for Emergency Situations', Handbook on Decision Support Systems, Volume 2, pp. 39-63.

Waugh, W.L. and Streib, G. (2006), 'Collaboration and Leadership for Effective Emergency Management', Public Administration Review, Volume 66, Number s1, pp. 131-140.

Weber, K. and Glynn, M.A. (2006), 'Making Sense with Institutions: Context, Thought and Action in Karl Weick's Theory', Organization Studies, Volume 27, Number 11, pp. 1639-1660.

Weick, K.E. (1990), 'The Vulnerable System: An Analysis of the Tenerife Air Disaster', Journal of Management, Volume 16, Number 3, pp. 571-593.

Weick, K.E. (1993), 'The Collapse of Sensemaking in Organizations: The Mann Gulch Disaster', Administrative Science Quarterly, Volume 38, Number 4, Pp. 628-652.
Weick, K.E. (1995), Sensemaking in Organizations, Vol. 3, Sage Publications, Incorporated, Thousand Oaks, CA.

Weick, K.E., Sutcliffe, K.M. and Obstfeld, D. (1999), 'Organizing for High Reliability: Processes of Collective Mindfulness', Research in Organizational Behaviour, Volume 1, pp. 81-123.

Weick, K.E., Sutcliffe, K.M. and Obstfeld, D. (2005), 'Organizing and the Process of Sensemaking', Organization Science, Volume 16, Number 4, pp. 409421.

Wolbers, J.J., Boersma, F.K. and de Heer, J. (2012), Netcentrisch Werken in Ontwikkeling. De Swart, Den Haag.

Yanow, D. (1997), 'Passionate Humility in Interpretive Policy and Administrative Analysis', Administrative Theory \& Praxis, Volume 19, Number 2, pp. 171177.

Yanow, D. and Schwartz-Shea, P. (2006), Interpretation and Method: Empirical Research Methods and the Interpretive Turn, ME Sharpe, Inc., New York, NY. 